\title{
AYLIK VE SEZONLUK YİRMİ DÖRT SAAT ISITMA DERECE SAAT DEĞERLERİNİN SAKARYA İÇIN TAHMİN EDİLMESİ
}

\author{
Yusuf ÇAY, Mustafa ERTÜRK*
}

Sakarya Uygulamalı Bilimler Üniversitesi, Teknoloji Fakültesi, Makina Mühendisliği Bölümü, Sakarya, Türkiye

\begin{tabular}{l}
\hline Anahtar Kelimeler \\
\hline Sakarya, \\
Saatlik Dış Hava Sıcaklık \\
Dağılımı, \\
Sezonluk Yirmi Dört Saatlik \\
Isıtma Derece Saat, \\
Aylık Yirmi Dört Saatlik \\
Isıtma Derece-Saat, \\
Íki Zaman Dilimi Arasında \\
Isıtma Derece Saat, \\
Isıtma Sistemlerinin Aylık ve \\
Sezonluk Çalışma Süresi.
\end{tabular}
Öz

Bu çalışmada Sakarya için son otuz altı yıllık meteorolojik veri seti kullanılmıştır. Bu veri seti ile 8760 saat içerisinde dış hava sıcaklığı $18^{\circ} \mathrm{C}$ altında olan her ay için yirmi dört saatlik dış hava sıcaklık dağılımları tespit edilerek ısıtma dönemi ayları (kasım, aralık, ocak, şubat, mart, nisan) belirlenmiştir. Bu yaklaşımla ısıtma dönemindeki herhangi bir ayın; herhangi bir saatinde, herhangi iki zaman dilimi arasında, toplam aylık olarak Isıtma Derece Saat (IDS) değeri tahmin edilmiştir. Ayrıca sezonluk, sezondaki herhangi bir saatteki ve herhangi iki zaman dilimi arasındaki IDS değeri de tahmin edilmiştir. Sakarya ili için en yüksek ısıtma enerji ihtiyacı üç farklı İç Ortam Referans Sıcaklığı (IORS) içinde ocak ayında 06:00 - 07:00 saatleri arasında olduğu tespit edilmiştir. Sakarya'daki bir binada ısıtma sezonu boyunca İORS $25^{\circ} \mathrm{C}$ seçildiğinde IDS değeri $61112.3^{\circ} \mathrm{C}$ saat, IORS $22^{\circ} \mathrm{C}$ seçildiğinde IDS değeri 54567.3 ${ }^{\circ} \mathrm{C}$ saat, $20^{\circ} \mathrm{C}$ seçildiğinde IDS değeri $46516.3{ }^{\circ} \mathrm{C}$ saat olacağı tahmin edilmiștir. Getirilen bu yaklaşımla ısıtma dönemindeki her ayın 24 saati için 11 farklı İORS'na göre IDS değerleri ayrıntılı olarak ortaya konulmuştur.

\section{ESTIMATION OF MONTHLY AND SEASONAL TWENTY-FOUR-HOUR HEATING DEGREE HOUR VALUES FOR SAKARYA}

\begin{tabular}{l}
\hline Keywords \\
Sakarya, \\
Hourly Outside Temperature \\
Distribution, \\
Twenty-Four Hours Of \\
Seasonal Heating Degree \\
Hours, \\
Twenty-Four Hours Of \\
Heating Degree-Hour Per \\
Month, \\
Heating Degree Hour \\
Between Two Time Zones, \\
Monthly And Seasonal \\
Working Time Of Heating \\
Systems.
\end{tabular}

\begin{abstract}
In this study, the Sakarya meteorological dataset for the last thirty-six years was used. With this dataset, within 8760 hours, the distribution of twenty-four-hour external air temperature below $18^{\circ} \mathrm{C}$ for each month were identified and the heating period months were determined (November, December, January, February, March, April). With this approach, for any month in the heating period, in any hour and between any two time periods the total monthly Heating Degree Hour (HDH) values were estimated. Additionally, the seasonal HDH value for any hour in the season and between any two time periods was predicted. The highest heating energy requirements for Sakarya province were identified to be between 06:00-07:00 in January for three different Indoor Reference Temperatures (IRT). During the heating season for a building in Sakarya, when the IRT is chosen as $25^{\circ} \mathrm{C}$, the HDH value is predicted to be $61112.3^{\circ} \mathrm{C}$ hours; when IRT is chosen as $22{ }^{\circ} \mathrm{C}$, the HDH value is predicted as $54567.3^{\circ} \mathrm{C}$ hours; and when the IRT is chosen as $20^{\circ} \mathrm{C}$, the $\mathrm{HDH}$ value is predicted to be $46516.3{ }^{\circ} \mathrm{C}$ hours. With this approach, the $\mathrm{HDH}$ values are revealed in detail according to 11 different IRT for 24-hour periods in every month of the heating period.
\end{abstract}

\section{Alıntı / Cite}

Çay, Y., Ertürk, M., (2021). Aylık ve Sezonluk Yirmi Dört Saat Isıtma Derece Saat Değerlerinin Sakarya İçin Tahmin Edilmesi, Mühendislik Bilimleri ve Tasarım Dergisi, 9(2), 616-627.

\begin{tabular}{l|l|l}
\hline Yazar Kimliği / Author ID (ORCID Number) & Makale Süreci / Article Process \\
\hline Y. Çay, 0000-0003-4007-6168 & Başvuru Tarihi / Submission Date & 30.08 .2020 \\
M. Ertürk, 0000-0002-0517-6940 & Revizyon Tarihi / Revision Date & 05.10 .2020 \\
& Kabul Tarihi / Accepted Date & 03.03 .2021 \\
& Yayım Tarihi / Published Date & 20.06 .2021 \\
\hline
\end{tabular}

\footnotetext{
* İlgili yazar / Corresponding author: mustafaerturk@subu.edu.tr,+90-264-6160221
} 


\section{Giriş (Introduction)}

Ulusal bazda kısa, uzun dönemli enerji tüketim, üretim tahmini ve modellemesi, tesis ve yatırımlar için en önemli parametrelerdendir. Saatlik tahmini enerji tüketimi üretim kontrolü ve planlaması için gereklidir. Günlük, haftalık, aylık ve yıllık olarak yapılan tahminler ise bakım programları ve tesis planlaması için gereklidir. Bu tahminlerle toplam enerji tüketimi içinde konut sektörünün payını ortaya çıkarmada ve aileler için uygun verimli ısıtma sistemini belirlemede de kolaylık sağlayacağı için önem arz etmektedir (Dilmaç. 2009). Kapalı hacimlerin ısıtılması amacıyla sezonluk enerji ihtiyacı mimari tasarım, malzeme karakteristikleri, meteorolojik dıș hava sıcaklık ölçümleri ve bölge nüfusuna bağlı olarak belirlenebilir(Durmayaz ve Kadığlu, 2003). Isıtma ve soğutma sistemlerinin tasarımı hesaplamalarında, kapalı hacimlerde enerji analizi hesaplamalarında iklim verileri en önemli parametrelerden birisidir(Bulut vd., 2002). Farklı enerji analizleri için farklı meteorolojik dış hava sıcaklık verileriyle yapılmaktadır. Enerji ve iklimlendirme sistemlerinin analizinde dış hava sıcaklık verileri son derece önem arz etmektedir(Büyükalaca ve Bulut, 2003).Binalarda ve iklimlendirme sistemleri için çeşitli enerji tahmin yöntemleri geliştirilmiştir. Bu yöntemlerin verdikleri sonuçların gerçeğe uygunlukları karmaşıklık derecelerine göre değişmektedir. Genel olarak bu yöntemler ikiye ayrılır. Bunlardan birincisi doğrulukları ve sonuçları açısından sınırlı olmasına rağmen derece gün, derece saat ve bin yöntemlerini içine alan statik yöntemlerdir. Diğeri ise binanın dinamik davranışı göz önüne alınan dinamik yöntemler olup daha çok bina enerji simülasyonu olarak bilinirler(Büyükalaca vd., 2001). Kapalı hacimlerde iç ortam sıcaklığındaki küçük değişiklikler ısıtma amaçlı enerji tüketiminin azalmasına sebep olmaktadır(Oktay vd., 2011) Isıtma amaçlı enerjisi tüketiminde azalma sera gazı salınımını azalmasına neden olmaktadır(Coşkun, 2010).Isıtma ve soğutma amaçlı tüketimi hesaplamalarında derece-gün, derece-sat yöntemleri kullanılmaktadır(Sarak ve Satman, 2001]. Avustralya'da yapılan bir araştırmada, iç ortam sıcaklıklarındaki değişikliklerle ısıtma amaçlı enerji tüketiminde $\% 15$ ile $\% 30$ 'luk enerji tasarrufu yapılabileceği ortaya konulmuştur(Haas vd., 1998). Derece-saat değerleriyle isıtma-soğutma amaçlı enerji ihtiyacından, duvarlarda ve borularda optimum izolasyon kalınlığı hesaplamalarına, doğal gaz boru çapları hesaplamalarına kadar çok farklı alanlarda kullanılmaktadır (Coşkun vd., 2009). Derece-saat değerleriyle ısıtmasoğutma amaçlı enerji ihtiyacından, duvarlarda ve borularda optimum izolasyon kalınlığı hesaplamalarına, doğal gaz boru çapları hesaplamalarına kadar çok farklı alanlarda kullanılmaktadır (Budescu vd., 1999; Durmayaz vd., 2000). Literatürde ısıtma ve soğutma derece-saat değerleri sezonluk olarak iç ortam referans sıcaklıklarına göre hem Türkiye'deki şehirler (Coşkun vd., 2009; Sarak ve Satman. 2003) hem de dünyanın birçok şehirleri (Dombaycl, 2009) için olmasına rağmen ısıtma sezonundaki her ayın herhangi bir zamanındaki veya iki zaman dilimi arasındaki derece-saat değerleri konusunda çalışma sayısı sınırlıdır. Bu çalışmada Sakarya için $18-28{ }^{\circ} \mathrm{C}$ iç ortam referans sıcaklığına göre ısıtma mevsimindeki aylar, bu aylar içerisindeki 24 saatlik IDSD, aylık IDSD, ısıtma dönemi IDSD tablolar ve grafikler halinde açılkanmıștır

\section{Materyal ve Yöntem (Material and Method)}

Bu çalışmada Devlet Meteoroloji Genel Müdürlüğü'nden 1972-2018 yılları arasında Sakarya için temin edilen meteorolojik veri seti kullanılmıștır. Bu veri seti Sakarya'da bulunan tüm meteorolojik istasyonlardan kayıt altına alınan 8760 saatlik dış hava sıcaklık dağılımlarıdır. Bu veri seti yazılan visual basic tabanlı geliştirilen iki adet yazılıma aktarılarak Sakarya için ısıtma dönemindeki her ay için ve sezonluk yirmi dört saatlik ayrıntılı hesaplamalar tablolar halinde literatüre kazandırılmıştır. Bu yaklaşımla; ısıtma dönemindeki herhangi bir ayın herhangi iki zaman dilimi arasında, aylık veya istenilen ayların istenilen saatlerinde veya iki zaman dilimi arasında on bir farklı iç ortam referans sıcaklığına göre IDS değeri tahmin edilmiştir

\subsection{Saatlik Bazda Dış Hava Sıcaklık Dağılım Tahmini (Estimation of Outdoor Temperature Distribution on Hourly Basis)}

Isı kaybı ve ısı kazancı hesaplamalarında kullanılan dış ortam referans sıcaklık değerleri sırasıyla belirli bir tekrar frekansına karşılık gelen sıcaklıklar olarak tespit edilir. Isıtma ve soğutma amaçlı tespit edilen DORS değerleri sezon boyunca sabit olarak alınmaktadır(Büyükalaca ve Bulut, 2003). Yalıtımsız binada dıș hava sıcaklığı $18^{\circ} \mathrm{C}$ ve altında ısıtma ihtiyacı olmaktadır(Büyükalaca vd., 2001). Bu çalışmada Sakarya'daki binaların yalıtımsız olduğu varsayılarak hesaplamalar yapılmıștır. Çalışmanın bu aşamasında Meteorolojik veri setindeki 24 saatlik dış hava sıcaklıkları birinci yazılıma aktarılarak her ayın 24 saati için ayrı ayrı ve sezonluk olmak üzere Yıllık Ortalama Dış Hava Sıcaklık Dağılımı (YODHSD) 24 adet analiz çalışmasıyla tahmin edilmiştir. Bu dağılım geliştirilen ikinci yazılıma taşınarak $18^{\circ} \mathrm{C}$ ve altındaki dış hava sıcaklıkları 8760 saat içerisinde görülme sayısı günün yirmi dört saati için ayrı ayrı 24 analiz yapılmıştır. Analiz sonuçlarına göre Sakarya için ısıtma mevsimi kasım ayında başlamakta nisan ayında sona erdiği tespit edilmiştir. Analiz sonuçları soğutma dönemindeki tüm aylar ve sezonluk olmak üzere 24 saatlik YODHSD 24 adet tablo haline dönüştürülmüştür. Bu tablolarla yılın on iki ayı ve yıllık 24 saatlik ortalama dış ortam sıcaklıkları o ay içerisinde 8760 saat içerisinde görülme sıklıkları (yüzde olarak sayısı) $1^{\circ} \mathrm{C}$ farkla ortaya konulmuştur. DHSD'larıyla ilgili 24 adet tablo üçüncü yazllıma giriş olarak hazırlanmıştır. Örnek olarak 23:00 -24:00 saatleri arasındaki analiz sonuçları Tablo 1' de verilmiştir. Tablo 1'de her ay için 8760 saat 
içerisinde görülme sayısı ve ısıtma dönemindeki tüm ayların Yıllık Ortalama Dış Hava Sıcaklık Dağılımı YODHSD \% olarak verilmiştir.

Tablo.1 Sakarya 23:00 -24:00 Saatleri arasında Yıllık Ortalama Dış Hava Sıcaklık Dağılımı (Annual Average Outdoor Air Temperature Distribution between 23:00 - 24:00 for Sakarya)

\begin{tabular}{|c|c|c|c|c|c|c|c|c|}
\hline \multicolumn{9}{|c|}{ SAKARYA SAAT 23:00-24:00 } \\
\hline \multirow{2}{*}{$\begin{array}{c}\text { DHSD } \\
{\left[{ }^{\circ} \mathrm{C}\right]}\end{array}$} & \multicolumn{7}{|c|}{ SAATLIKK BAZDA AYLARA GÖRE ORTALAMA DHSD [\% ] } & \multirow{2}{*}{$\begin{array}{c}\text { YODHSD } \\
{[\%]}\end{array}$} \\
\hline & Ocak & Șubat & Mart & Nisan & Ekim & Kasım & Aralık & \\
\hline$-8,5$ & 0 & 0 & 0 & 0 & 0 & 0 & 0 & 0 \\
\hline$-7,5$ & 0 & 0,09 & 0 & 0 & 0 & 0 & 0 & 0,012857 \\
\hline$-6,5$ & 0,08 & 0,09 & 0,09 & 0 & 0 & 0 & 0 & 0,037143 \\
\hline$-5,5$ & 0,08 & 0,45 & 0 & 0 & 0 & 0 & 0 & 0,075714 \\
\hline$-4,5$ & 0,25 & 0,18 & 0 & 0 & 0 & 0 & 0,2 & 0,09 \\
\hline$-3,5$ & 0,42 & 0,81 & 0,26 & 0 & 0 & 0 & 0,1 & 0,227143 \\
\hline$-2,5$ & 1,02 & 1,35 & 0,17 & 0 & 0 & 0 & 0,3 & 0,405714 \\
\hline$-1,5$ & 1,53 & 2,61 & 0,61 & 0 & 0 & 0 & 0,4 & 0,735714 \\
\hline$-0,5$ & 3,47 & 3,77 & 0,52 & 0 & 0 & 0,1 & 1,81 & 1,381429 \\
\hline 0,5 & 6,19 & 5,75 & 3,91 & 0,1 & 0 & 0,94 & 4,52 & 3,058571 \\
\hline 1,5 & 6,44 & 6,65 & 4 & 0,62 & 0 & 1,77 & 5,13 & 3,515714 \\
\hline 2,5 & 9,49 & 6,47 & 5,83 & 0,21 & 0,1 & 3,12 & 6,13 & 4,478571 \\
\hline 3,5 & 8,47 & 7,19 & 7,48 & 1,77 & 0,4 & 4,89 & 6,93 & 5,304286 \\
\hline 4,5 & 7,88 & 7,91 & 9,39 & 2,29 & 0,3 & 5,09 & 7,34 & 5,742857 \\
\hline 5,5 & 7,63 & 7,55 & 9,57 & 4,05 & 0,7 & 5,93 & 11,26 & 6,67 \\
\hline 6,5 & 5,25 & 6,83 & 7,13 & 6,34 & 1,11 & 5,61 & 9,45 & 5,96 \\
\hline 7,5 & 6,27 & 4,22 & 7,83 & 11,02 & 3,32 & 7,59 & 8,14 & 6,912857 \\
\hline 8,5 & 4,41 & 4,22 & 6,96 & 11,85 & 4,23 & 10,29 & 7,74 & 7,1 \\
\hline 9,5 & 2,97 & 3,14 & 4,17 & 11,23 & 7,14 & 8,42 & 6,23 & 6,185714 \\
\hline 10,5 & 2,88 & 1,89 & 4,26 & 10,6 & 7,44 & 11,64 & 5,33 & 6,291429 \\
\hline 11,5 & 2,2 & 2,34 & 4,43 & 8,73 & 8,55 & 7,69 & 4,42 & 5,48 \\
\hline 12,5 & 2,03 & 1,98 & 3,57 & 8,11 & 9,66 & 7,8 & 3,92 & 5,295714 \\
\hline 13,5 & 1,61 & 1,08 & 1,65 & 6,03 & 12,98 & 6,34 & 2,71 & 4,628571 \\
\hline 14,5 & 1,27 & 1,35 & 1,3 & 4,99 & 11,57 & 4,05 & 2,31 & 3,834286 \\
\hline 15,5 & 1,1 & 0,72 & 0,87 & 3,85 & 12,07 & 2,39 & 2,21 & 3,315714 \\
\hline 16,5 & 0,68 & 0,99 & 0,7 & 3,01 & 7,75 & 1,87 & 1,31 & 2,33 \\
\hline 17,5 & 0,17 & 0,18 & 0,35 & 1,46 & 4,83 & 1,14 & 0,5 & 1,232857 \\
\hline 18,5 & 0,08 & 0,81 & 0,17 & 0,83 & 3,32 & 1,14 & 0,6 & 0,992857 \\
\hline 19,5 & 0,08 & 0,45 & 0,52 & 1,14 & 1,71 & 0,73 & 0,3 & 0,704286 \\
\hline 20,5 & 3,56 & 0,18 & 0 & 0,42 & 0,91 & 0,62 & 0,2 & 0,841429 \\
\hline 21,5 & 3,98 & 4,22 & 0,26 & 0,1 & 0,91 & 0,31 & 0,2 & 1,425714 \\
\hline 22,5 & 3,98 & 4,76 & 0,09 & 0,31 & 0,3 & 0,1 & 0 & 1,362857 \\
\hline 23,5 & 4,49 & 4,85 & 0,09 & 0,42 & 0,1 & 0,1 & 0,1 & 1,45 \\
\hline 24,5 & 0 & 4,94 & 0 & 0,1 & 0,2 & 0,1 & 0,1 & 0,777143 \\
\hline 25,5 & 0 & 0 & 0 & 0 & 0,1 & 0 & 0,1 & 0,028571 \\
\hline 26,5 & 0 & 0 & 0 & 0,1 & 0 & 0 & 0 & 0,014286 \\
\hline 27,5 & 0 & 0 & 0,09 & 0 & 0 & 0,1 & 0 & 0,027143 \\
\hline 28,5 & 0 & 0 & 3,74 & 0,1 & 0 & 0,1 & 0 & 0,562857 \\
\hline 29,5 & 0 & 0 & 4,26 & 0,1 & 0 & 0 & 0 & 0,622857 \\
\hline 30,5 & 0 & 0 & 3,57 & 0,1 & 0,1 & 0 & 0 & 0,538571 \\
\hline 31,5 & 0 & 0 & 2,17 & 0 & 0,1 & 0 & 0 & 0,324286 \\
\hline 32,5 & 0 & 0 & 0 & 0 & 0,1 & 0 & 0 & 0,014286 \\
\hline
\end{tabular}

\subsubsection{Derece Zaman Hesaplama Yöntemleri (Degree Time Calculation Methods)}

Literatürde derece zaman yöntemiyle ilgili üç farklı yöntem (bin, derece gün, derece saat) bulunmaktadır(Badescu, V., Zamfir, 1999). Derece zaman yöntemleri hesaplamalarında derece saat yöntemi en hassas yöntem olduğu için (Büyükalaca vd., 2001) bu çalışmada tercih edilmiştir.

\subsubsection{Derece Saat Yöntemi (Degree Hour Method)}

Kapalı hacimlerin ısıtılması veya soğutulması için gerekli enerji IDS yöntemi ile kolaylıkla tahmin edilebilir. Bu yöntemde ısıtma ve soğutma amaçlı gerekli olan enerjinin, dış ortam sıcaklığı ve denge noktası sıcaklığı arasındaki farkla orantılı olduğu kabul edilir. IDS yönteminde, en az on yıl geçmişe yönelik yıllık 8760 saatlik ortalama ölçüm 
değerlerinin olması gereklidir. Denge noktası sıcaklığı, bir binada ısıtmaya veya soğutmaya ihtiyaç duyulmadığı durumdaki dış ortam sıcaklığıdır. Genelde, yalıtımsız bir bina için derece saat değerleri ısıtmada $18^{\circ} \mathrm{C}$ denge sıcaklığı için hesaplanır. IDS hesaplamalarında bunun içinde bir yll içerisinde toplam 8760 saatlik ölçüm değerlerinin olması gerekir. IDS değeri aşağıdaki denklemlerle belirlenir (Durmayaz vd., 2000).

$$
I D S=(1 \text { saat }) \sum \text { saatler }\left(T_{b}-T_{d}\right)+\quad\left[{ }^{\circ} \mathrm{C} . \text { saat }\right]
$$

$\mathrm{T}_{\mathrm{b}}$ : Saatlik iç ortam sıcaklığ $\left[{ }^{\circ} \mathrm{C}\right]$.

$\mathrm{Td}$ : Saatlik dış ortam sıcaklığı $\left[{ }^{\circ} \mathrm{C}\right]$.

Denklemlerdeki parantezin üzerindeki ' + ' işareti sadece pozitif değerlerin hesaba katılacağını göstermektedir. Isıtma derece saat (IDS), aylık veya yıllık ısıtma enerjisi gereksinimi, Eşitlik 2'den hesaplanabilir.

$$
Q_{\imath}=\frac{K_{\text {top }}}{\eta} I D S\left(\frac{1}{1000}\right) \quad[\mathrm{kWh}]
$$

$\mathrm{Q}_{1} ;$ isitma enerjisi gereksinimi,

$\eta$; isitma sistemi verimini,

$\mathrm{K}_{\text {top; }}$ dış duvarın toplam ısı transfer katsayısını $\left[\mathrm{W} / \mathrm{m}^{2} \mathrm{~K}\right]$ ifade etmektedir

\section{Bulgular (Findings)}

Bu bölümde ikinci yazılımla ısıtma dönemi her ayı ve her saati için ayrı ayrı elde edilen 24 adet YODHSD üçüncü yazılıma aktarılmıştır. Üçüncü yazılımla 11 farklı iç ortam sıcaklı̆̆ına göre soğutma döneminin her ayı için 24 saatlik IDS değerleri analiz edilmiştir. Analiz sonuçları örnek Tablo 1-14 ve Şekil 1-2'de verilmiştir.

\subsection{Soğutma Dönemi Ayları ve Sezonluk Isıtma Derece Saat (IDS) Değerlerinin Saatlik ve Yirmi Dört Saatlik Olarak Tahmin Edilmesi (Hourly and Twenty-four-hour Estimation of Cooling Period Months and Seasonal Heating Degree Hour (HDH) Values)}

Bu çalışmada YODHSD günün her saati için ayrı ayrı visual basic tabanlı geliştirilen üçüncü yazılıma aktarılmıştır. Bu yazılım, Sakarya için soğutma dönemi her ayı ve sezonu için 11 farklı $\left(18-28^{\circ} \mathrm{C}\right)$ iç ortam referans sıcaklığına göre saatlik bazda IDS değerlerini 24 saatlik olarak birer saat aralıklarla hesaplayıp tablo haline getirmektedir. Bu yaklaşımla Sakarya için 11 farklı $\left(18-28^{\circ} \mathrm{C}\right)$ İORS'na göre soğutma dönemi aylarının her biri için ve soğutma sezonu olmak üzere 24 saatlik ve her saat için IDS değeri ayrı ayrı hesaplanmıştır. IDS değeri sezondaki her ay, günün 24 saati için ayrı ayrı olarak verilmesi aylık bazdaki değişimi ayrıntılı olarak ortaya koymaktadır.

Sakarya $20^{\circ} \mathrm{C}$ IORS'na IDS değeri sezondaki her ay (kasım, aralık, ocak, şubat, mart, nisan)için 24 saat (00:00-01:00 ve 23:00-24:00) olmak üzere sezondaki her ayın istenilen saatinde, iki zaman dilimi arasında, aylık toplam olmak üzere hesaplanmıștır. Ayrıca sezonluk olarakta hesaplamalar yapılmıștır. Hesaplama sonuçları Tablo 2- 'de verilmiştir. Bu tabloların kullanımıyla ilgili açıklama Tablo 2'de verilmiştir. Bu tablonun 1. sütununda günün 24 saati (birer saat aralıklarla), iç sütunlarda soğutma dönemi ayları ve son sütunda ise sezondaki tüm ayların saatlik ve 24 saatlik toplm IDS değerleri verilmiştir. Bu yaklaşımla ısıtma dönemindeki her ayın herhangi bir saatindeki IDSD, herhangi iki zaman dilimi arasındaki IDS değeri, her ay için toplam IDS değeri ve ısıtma dönemi 24 saatlik IDS değeri Sakarya için literatüre kazandırılmıştır.

Tablo 2. $20^{\circ} \mathrm{C}$ İORS' na Göre Dört Saatlik IDS Değeri (Four Hour Heating Degree Hour(HDH) Value According to $20{ }^{\circ} \mathrm{C}$ Indoor Reference Temperature for Sakarya

\begin{tabular}{|c|c|c|c|c|c|c|c|}
\hline \multicolumn{8}{|c|}{ Sakarya $20^{\circ} \mathrm{C}$ İORS Göre Dört Saatlik (13:00- 17:00) IDS Değeri } \\
\hline \multirow[b]{2}{*}{$\begin{array}{c}\text { Bir saat aralıklarla } \\
\qquad 4 \text { saat }\end{array}$} & \multicolumn{6}{|c|}{ Isitma Sezonundaki Aylar } & \multirow[b]{2}{*}{$\begin{array}{c}\text { Sezonluk IDS } \\
{\left[{ }^{\circ} \text { Csaat }\right]}\end{array}$} \\
\hline & $\begin{array}{c}\text { Kasım } \\
{\left[{ }^{\circ} \text { Csaat }\right]}\end{array}$ & $\begin{array}{c}\text { Aralık } \\
{\left[{ }^{\circ} \text { Csaat }\right]}\end{array}$ & $\begin{array}{c}\text { Ocak } \\
{\left[{ }^{\circ} \text { Csaat }\right]}\end{array}$ & $\begin{array}{c}\text { Subat } \\
{\left[{ }^{\circ} \mathrm{Csaat}\right]}\end{array}$ & $\begin{array}{c}\text { Mart } \\
{\left[{ }^{\circ} \mathrm{Csaat}\right]}\end{array}$ & $\begin{array}{c}\text { Nisan } \\
{\left[{ }^{\circ} \text { Csaat }\right]}\end{array}$ & \\
\hline $13: 00-14: 00$ & 174,7 & 298,3 & 312,1 & 304,8 & 248,2 & 119,6 & 1457,7 \\
\hline $14: 00-15: 00$ & 180,4 & 301,9 & 331,4 & 330,0 & 251,9 & 124,4 & 1520,0 \\
\hline 15:00-16:00 & 196,4 & 315,9 & 321,3 & 335,5 & 263,1 & 135,7 & 1567,9 \\
\hline $16: 00-17: 00$ & 224,8 & 337,4 & 368,6 & 355,6 & 282,2 & 152,0 & 1720,5 \\
\hline 4 saatlik toplam IDS değeri & 776,3 & 1253,5 & 1333,4 & 1325,9 & 1045,4 & 531,7 & 6266,2 \\
\hline
\end{tabular}
Sakarya $20^{\circ} \mathrm{C}$ IORS Göre Dört Saatlik (13:00- 17:00) IDS Değeri

Tablo 2'de 13:00 -17:00 arasında $20^{\circ} \mathrm{C}$ İORS göre her ay ve dört saat için ayrı ayrı olmak aylık ve sezonluk IDS değerleri verilmiştir. Bu tabloda aylık bazda istenilen saat aralığında, herhangi iki ay arasında IDS değerleri ve sezonluk IDS değerleri bulunabilmektedir. Örnek olarak; 13:00-14:00 ile 16:00-17:00 saatleri arasında IDS değeri farkı kasım ayında 50.1 IDS iken ocak ayında 56.5 IDS, nisan ayında 32.4 IDS olarak istenilen iki zaman dilimi 
arasındaki IDS değerlerinin farkı alınarak hesaplanabilir. Tablo 3'te Sakarya $20^{\circ} \mathrm{C}$ İORS'na göre 24 Saatlik IDS Değerleri verilmiştir. Tablo 4 kesintili çalışacak (10:00-22:00 saatleri arasında) alışveriş merkezleri için hazırlanmıștır. Bu yaklașımla 12 saatlik IDS değerleri sezondaki tüm aylar için saatlik, iki zaman dilimi arasındaki IDS değerleri ve sezonluk IDS değerleri de ayrı ayrı tahmin edilmiştir.

Tablo 3. Sakarya $20^{\circ} \mathrm{C}$ İç Ortam Referans Sıcaklığına Göre 24 Saatlik IDS Değeri (-24-Hour Heating Degree Hour(HDH) Value According to Sakarya $20^{\circ} \mathrm{C}$ Indoor Reference Temperature for Sakarya)

\begin{tabular}{|c|c|c|c|c|c|c|c|}
\hline \multicolumn{8}{|c|}{ Sakarya $20^{\circ} \mathrm{C}$ İç Ortam Referans Sicaklığına Göre 24 Saat IDS Değeri } \\
\hline \multirow[b]{2}{*}{$\begin{array}{l}\text { Bir saat aralıklarla } \\
24 \text { saat }\end{array}$} & \multicolumn{6}{|c|}{ Isitma Sezonundaki Aylar } & \multirow[b]{2}{*}{$\begin{array}{c}\text { Sezonluk IDS } \\
{\left[{ }^{\circ} \text { Csaat }\right]}\end{array}$} \\
\hline & $\begin{array}{c}\text { Kasım } \\
{\left[{ }^{\circ} \text { Csaat] }\right.}\end{array}$ & $\begin{array}{c}\text { Aralık } \\
{\left[{ }^{\circ} \mathrm{Csaat}\right]}\end{array}$ & $\begin{array}{c}\text { Ocak } \\
{\left[{ }^{\circ} \mathrm{Csaat}\right]}\end{array}$ & $\begin{array}{c}\text { Şubat } \\
{\left[{ }^{\circ} \mathrm{Csaat}\right]}\end{array}$ & $\begin{array}{c}\text { Mart } \\
{\left[{ }^{\circ} \mathrm{Csa} \text { t }\right]}\end{array}$ & $\begin{array}{c}\text { Nisan } \\
{\left[{ }^{\circ} \mathrm{Csaat}\right]}\end{array}$ & \\
\hline 00:00-01:00 & 330,3 & 406,2 & 388,8 & 380,9 & 352,4 & 311,5 & 2170,0 \\
\hline 01:00-02:00 & 335,4 & 411,0 & 398,4 & 391,1 & 353,7 & 303,5 & 2193,2 \\
\hline 02:00-03:00 & 341,2 & 415,7 & 401,9 & 383,1 & 365,5 & 329,1 & 2236,4 \\
\hline 03:00-04:00 & 346,2 & 418,9 & 405,2 & 392,4 & 365,1 & 334,9 & 2262,7 \\
\hline $04: 00-05: 00$ & 350,5 & 422,2 & 412,5 & 385,5 & 377,8 & 338,8 & 2287,2 \\
\hline 05:00-06:00 & 354,1 & 425,6 & 394,6 & 421,4 & 416,0 & 338,2 & 2350,0 \\
\hline 06:00-07:00 & 354,6 & 425,6 & 394,0 & 421,9 & 391,9 & 314,1 & 2302,2 \\
\hline 07:00-08:00 & 335,3 & 426,3 & 393,3 & 417,2 & 371,0 & 268,8 & 2211,8 \\
\hline 08:00-09:00 & 298,3 & 396,4 & 386,9 & 369,9 & 317,5 & 220,2 & 1989,1 \\
\hline 9:00-10:00 & 257,7 & 372,0 & 349,1 & 368,6 & 305,2 & 173,7 & 1826,3 \\
\hline $10: 00-11: 00$ & 222,7 & 343,8 & 329,8 & 361,2 & 287,9 & 150,8 & 1696,3 \\
\hline $11: 00-12: 00$ & 198,7 & 323,1 & 310,0 & 335,4 & 271,4 & 135,8 & 1574,3 \\
\hline $12: 00-13: 00$ & 183,1 & 306,2 & 313,0 & 310,5 & 259,0 & 125,5 & 1497,3 \\
\hline $13: 00-14: 00$ & 174,7 & 298,3 & 312,1 & 304,8 & 248,2 & 119,6 & 1457,7 \\
\hline $14: 00-15: 00$ & 180,4 & 301,9 & 331,4 & 330,0 & 251,9 & 124,4 & 1520,0 \\
\hline 15:00-16:00 & 196,4 & 315,9 & 321,3 & 335,5 & 263,1 & 135,7 & 1567,8 \\
\hline $16: 00-17: 00$ & 224,8 & 337,4 & 368,6 & 355,6 & 282,2 & 152,0 & 1720,5 \\
\hline 17:00-18:00 & 250,6 & 355,3 & 331,2 & 320,1 & 306,9 & 176,7 & 1740,7 \\
\hline $18: 00-19: 00$ & 270,4 & 367,6 & 340,7 & 341,6 & 303,9 & 195,8 & 1820,1 \\
\hline 19:00-20:00 & 376,2 & 376,2 & 352,8 & 336,4 & 297,8 & 230,7 & 1970,1 \\
\hline $20: 00-21: 00$ & 297,6 & 339,6 & 365,4 & 350,1 & 309,0 & 249,5 & 1911,2 \\
\hline $21: 00-22: 00$ & 308,8 & 390,0 & 381,4 & 365,7 & 317,9 & 269,6 & 2033,4 \\
\hline $22: 00-23: 00$ & 318,8 & 394,9 & 379,9 & 362,9 & 332,9 & 253,3 & 2042,7 \\
\hline $23: 00-24: 00$ & 325,7 & 399,9 & 385,4 & 373,5 & 354,8 & 295,7 & 2135,1 \\
\hline 24 saatlik toplam & 6832,5 & 8969,8 & 8747,6 & 8715,2 & 7703,1 & 5548,0 & 46516,3 \\
\hline
\end{tabular}

Tablo 4. Sakarya $20^{\circ} \mathrm{C}$ İç Ortam Referans Sıcaklığına Göre 12 Saatlik IDS Değeri (- 12- Heating Degree Hour(HDH) Value According to Sakarya $20^{\circ} \mathrm{C}$ Indoor Reference Temperature(IRT)

\begin{tabular}{|c|c|c|c|c|c|c|c|}
\hline \multicolumn{8}{|c|}{ Sakarya $20^{\circ} \mathrm{C}$ İç Ortam Referans Sicakliğina Göre 12 Saatlik (10:00-22:00) IDS Değeri } \\
\hline \multirow[b]{2}{*}{$\begin{array}{c}\text { Bir saat aralıklarla } \\
12 \text { saat }\end{array}$} & \multicolumn{6}{|c|}{ Isitma Sezonundaki Aylar } & \multirow[b]{2}{*}{$\begin{array}{c}\text { Sezonluk IDS } \\
{\left[{ }^{\circ} \text { Csaat }\right]}\end{array}$} \\
\hline & $\begin{array}{c}\text { Kasım } \\
{\left[{ }^{\circ} \text { Csaat }\right]}\end{array}$ & $\begin{array}{c}\text { Aralık } \\
{\left[{ }^{\circ} \mathrm{Csaat}\right]}\end{array}$ & $\begin{array}{c}\text { Ocak } \\
{\left[{ }^{\circ} \text { Csaat }\right]}\end{array}$ & $\begin{array}{c}\text { Subat } \\
{\left[{ }^{\circ} \text { Csaat }\right]}\end{array}$ & $\begin{array}{c}\text { Mart } \\
{\left[{ }^{\circ} \text { Csaat }\right]}\end{array}$ & $\begin{array}{c}\text { Nisan } \\
{\left[{ }^{\circ} \text { Csaat }\right]}\end{array}$ & \\
\hline 10:00-11:00 & 222,7 & 343,8 & 329,8 & 361,2 & 287,9 & 150,8 & 1696,3 \\
\hline 11:00-12:00 & 198,7 & 323,1 & 310,0 & 335,4 & 271,4 & 135,8 & 1574,3 \\
\hline 12:00-13:00 & 183,1 & 306,2 & 313,0 & 310,5 & 259,0 & 125,5 & 1497,3 \\
\hline 13:00-14:00 & 174,7 & 298,3 & 312,1 & 304,8 & 248,2 & 119,6 & 1457,7 \\
\hline $14: 00-15: 00$ & 180,4 & 301,9 & 331,4 & 330,0 & 251,9 & 124,4 & 1520,0 \\
\hline $15: 00-16: 00$ & 196,4 & 315,9 & 321,3 & 335,5 & 263,1 & 135,7 & 1567,8 \\
\hline 16:00-17:00 & 224,8 & 337,4 & 368,6 & 355,6 & 282,2 & 152,0 & 1720,5 \\
\hline $17: 00-18: 00$ & 250,6 & 355,3 & 331,2 & 320,1 & 306,9 & 176,7 & 1740,7 \\
\hline $18: 00-19: 00$ & 270,4 & 367,6 & 340,7 & 341,6 & 303,9 & 195,8 & 1820,1 \\
\hline 19:00-20:00 & 376,2 & 376,2 & 352,8 & 336,4 & 297,8 & 230,7 & 1970,1 \\
\hline $20: 00-21: 00$ & 297,6 & 339,6 & 365,4 & 350,1 & 309,0 & 249,5 & 1911,2 \\
\hline $21: 00-22: 00$ & 308,8 & 390,0 & 381,4 & 365,7 & 317,9 & 269,6 & 2033,4 \\
\hline 12 saatlik toplam & 2884,4 & 4055,3 & 4057,7 & 4046,9 & 3399,2 & 2066,1 & 20509,6 \\
\hline
\end{tabular}


Tablo 5. Sakarya $22^{\circ} \mathrm{C}$ İORS' na Göre 24 Dört Saatlik IDS Değeri (-24-Hour Heating Degree Hour(HDH) Value According to $22^{\circ} \mathrm{C}$ Indoor Reference Temperature for Sakarya)

\begin{tabular}{|c|c|c|c|c|c|c|c|}
\hline \multicolumn{8}{|c|}{ Sakarya $22^{\circ} \mathrm{C}$ İç Ortam Referans Sıcaklığına Göre 24 Saat IDS Değeri } \\
\hline \multirow[b]{2}{*}{$\begin{array}{l}\text { Bir saat aralıklarla } \\
24 \text { saat }\end{array}$} & \multicolumn{6}{|c|}{ Isıtma Sezonundaki Aylar } & \multirow[b]{2}{*}{$\begin{array}{c}\text { Her saat için sezonluk } \\
\text { IDS } \\
{\left[{ }^{\circ} \mathrm{Csaat}\right]}\end{array}$} \\
\hline & $\begin{array}{c}\text { Kasım } \\
{\left[{ }^{\circ} \text { Csaat }\right]}\end{array}$ & $\begin{array}{c}\text { Aralık } \\
{\left[{ }^{\circ} \mathrm{Csaat}\right]}\end{array}$ & $\begin{array}{c}\text { Ocak } \\
{\left[{ }^{\circ} \text { Csaat }\right]}\end{array}$ & $\begin{array}{c}\text { Şubat } \\
{\left[{ }^{\circ} \mathrm{Csaat}\right]}\end{array}$ & $\begin{array}{c}\text { Mart } \\
{\left[{ }^{\circ} \text { Csaat }\right]}\end{array}$ & $\begin{array}{l}\text { Nisan } \\
{\left[{ }^{\circ} \text { Csaat }\right]}\end{array}$ & \\
\hline 00:00-01:00 & 391,7 & 467,9 & 443,0 & 432,1 & 403,8 & 372,6 & 2511,0 \\
\hline 01:00-02:00 & 396,8 & 472,8 & 453,4 & 443,1 & 404,4 & 361,2 & 2531,7 \\
\hline 02:00-03:00 & 402,3 & 477,6 & 457,0 & 432,8 & 417,2 & 390,1 & 2577,0 \\
\hline 03:00-04:00 & 407,4 & 480,7 & 460,4 & 442,9 & 416,3 & 395,8 & 2603,4 \\
\hline 04:00-05:00 & 411,9 & 483,8 & 470,3 & 434,6 & 430,2 & 399,5 & 2630,4 \\
\hline 05:00-06:00 & 415,6 & 487,4 & 447,5 & 474,8 & 473,5 & 399,3 & 2698,1 \\
\hline 06:00-07:00 & 416,2 & 487,4 & 447,3 & 475,2 & 446,9 & 375,1 & 2648,1 \\
\hline 07:00-08:00 & 396,3 & 488,0 & 446,3 & 471,1 & 426,3 & 328,2 & 2556,1 \\
\hline 08:00-09:00 & 359,1 & 457,8 & 443,6 & 420,6 & 370,1 & 277,2 & 2328,4 \\
\hline 9:00-10:00 & 317,5 & 433,5 & 398,5 & 422,6 & 360,9 & 224,5 & 2157,6 \\
\hline $10: 00-11: 00$ & 280,6 & 405,3 & 379,5 & 418,2 & 344,0 & 199,2 & 2026,8 \\
\hline $11: 00-12: 00$ & 254,1 & 384,5 & 359,5 & 391,6 & 326,5 & 182,1 & 1898,2 \\
\hline $12: 00-13: 00$ & 236,8 & 367,3 & 365,1 & 364,5 & 313,1 & 169,6 & 1816,4 \\
\hline $13: 00-14: 00$ & 227,5 & 359,3 & 365,8 & 359,0 & 301,3 & 162,5 & 1775,4 \\
\hline $14: 00-15: 00$ & 233,5 & 362,7 & 388,0 & 388,3 & 305,3 & 168,6 & 1846,3 \\
\hline $15: 00-16: 00$ & 252,4 & 377,1 & 374,6 & 393,4 & 318,0 & 182,4 & 1897,8 \\
\hline $16: 00-17: 00$ & 284,2 & 398,7 & 426,6 & 414,2 & 339,3 & 201,2 & 2064,2 \\
\hline $17: 00-18: 00$ & 311,7 & 416,9 & 381,0 & 370,0 & 365,9 & 230,2 & 2075,7 \\
\hline 18:00-19:00 & 331,7 & 429,4 & 391,1 & 392,4 & 358,8 & 249,7 & 2153,0 \\
\hline 19:00-20:00 & 438,0 & 438,0 & 404,1 & 385,1 & 349,0 & 289,6 & 2303,6 \\
\hline 20:00-21:00 & 358,9 & 394,4 & 419,6 & 399,5 & 359,8 & 309,7 & 2241,9 \\
\hline $21: 00-22: 00$ & 370,2 & 451,8 & 436,2 & 416,3 & 368,1 & 330,5 & 2373,2 \\
\hline $22: 00-23: 00$ & 380,2 & 456,7 & 434,0 & 412,4 & 384,0 & 307,7 & 2375,1 \\
\hline $23: 00-24: 00$ & 387,2 & 461,6 & 439,8 & 424,5 & 408,0 & 356,8 & 2477,8 \\
\hline 24 saatlik ToplamIDS Değeri & 8261,5 & 10440,6 & 10032,2 & 9979,1 & 8990,8 & 6863,1 & 54567,3 \\
\hline
\end{tabular}

Tablo 6, günün 16 saati (08:00-24:00) çalışacak kesintili ısıtma sistemleri için hazırlanmıştır.

Tablo 6. Sakarya $22^{\circ} \mathrm{C}$ İç Ortam Referans Sıcaklığına Göre 16 Saatlik IDS Değeri (16- Hour Heating Degree Hour(HDH) Value According to $22^{\circ} \mathrm{C}$ Indoor Reference Temperature for Sakarya)

\begin{tabular}{|c|c|c|c|c|c|c|c|}
\hline \multicolumn{8}{|c|}{ Sakarya $22^{\circ} \mathrm{C}$ İç Ortam Referans Sıcaklığına Göre 16 Saatlik (13:00- 17:00) IDS Değeri } \\
\hline \multirow[b]{2}{*}{$\begin{array}{c}\text { Bir saat aralıklarla } \\
16 \text { saat }\end{array}$} & \multicolumn{6}{|c|}{ Isitma Sezonundaki Aylar } & \multirow[b]{2}{*}{$\begin{array}{c}\text { Her saat için sezonluk } \\
\text { IDS } \\
{\left[{ }^{\circ} \mathrm{Csaat}\right]}\end{array}$} \\
\hline & $\begin{array}{l}\text { Kasım } \\
{\left[{ }^{\circ} \mathrm{Csaat}\right]}\end{array}$ & $\begin{array}{c}\text { Aralık } \\
{\left[{ }^{\circ} \mathrm{Csaat}\right]}\end{array}$ & $\begin{array}{c}\text { Ocak } \\
{\left[{ }^{\circ} \text { Csaat }\right]}\end{array}$ & $\begin{array}{c}\text { Şubat } \\
{\left[{ }^{\circ} \mathrm{Csaat}\right]}\end{array}$ & $\begin{array}{c}\text { Mart } \\
{\left[{ }^{\circ} \text { Csaat }\right]}\end{array}$ & $\begin{array}{l}\text { Nisan } \\
{\left[{ }^{\circ} \mathrm{Csaat}\right]}\end{array}$ & \\
\hline 08:00-09:00 & 359,1 & 457,8 & 443,6 & 420,6 & 370,1 & 277,2 & 2328,4 \\
\hline 9:00-10:00 & 317,5 & 433,5 & 398,5 & 422,6 & 360,9 & 224,5 & 2157,6 \\
\hline $10: 00-11: 00$ & 280,6 & 405,3 & 379,5 & 418,2 & 344,0 & 199,2 & 2026,8 \\
\hline $11: 00-12: 00$ & 254,1 & 384,5 & 359,5 & 391,6 & 326,5 & 182,1 & 1898,2 \\
\hline $12: 00-13: 00$ & 236,8 & 367,3 & 365,1 & 364,5 & 313,1 & 169,6 & 1816,4 \\
\hline $13: 00-14: 00$ & 227,5 & 359,3 & 365,8 & 359,0 & 301,3 & 162,5 & 1775,4 \\
\hline $14: 00-15: 00$ & 233,5 & 362,7 & 388,0 & 388,3 & 305,3 & 168,6 & 1846,3 \\
\hline $15: 00-16: 00$ & 252,4 & 377,1 & 374,6 & 393,4 & 318,0 & 182,4 & 1897,8 \\
\hline $16: 00-17: 00$ & 284,2 & 398,7 & 426,6 & 414,2 & 339,3 & 201,2 & 2064,2 \\
\hline 17:00-18:00 & 311,7 & 416,9 & 381,0 & 370,0 & 365,9 & 230,2 & 2075,7 \\
\hline $18: 00-19: 00$ & 331,7 & 429,4 & 391,1 & 392,4 & 358,8 & 249,7 & 2153,0 \\
\hline 19:00-20:00 & 438,0 & 438,0 & 404,1 & 385,1 & 349,0 & 289,6 & 2303,6 \\
\hline $20: 00-21: 00$ & 358,9 & 394,4 & 419,6 & 399,5 & 359,8 & 309,7 & 2241,9 \\
\hline $21: 00-22: 00$ & 370,2 & 451,8 & 436,2 & 416,3 & 368,1 & 330,5 & 2373,2 \\
\hline $22: 00-23: 00$ & 380,2 & 456,7 & 434,0 & 412,4 & 384,0 & 307,7 & 2375,1 \\
\hline $23: 00-24: 00$ & 387,2 & 461,6 & 439,8 & 424,5 & 408,0 & 356,8 & 2477,8 \\
\hline 16 Saatlik Toplam IDS Değeri & 8261,5 & 10440,6 & 10032,2 & 9979,1 & 8990,8 & 6863,1 & 54567,3 \\
\hline
\end{tabular}


Tablo 7. Sakarya $24^{\circ} \mathrm{C}$ İç Ortam Referans Sıcaklığına Göre 24 Saatlik IDS Değeri (- 24- Hour Heating Degree Hour(HDH) Value According to $24^{\circ} \mathrm{C}$ Indoor Reference Temperature for Sakarya)

\begin{tabular}{|c|c|c|c|c|c|c|c|}
\hline \multicolumn{8}{|c|}{ Sakarya $24^{\circ} \mathrm{C}$ İç Ortam Referans Sıcaklığına Göre 24 Saat IDS Değeri } \\
\hline \multirow[b]{2}{*}{$\begin{array}{c}\text { Bir saat aralıklarla } \\
24 \text { saat }\end{array}$} & \multicolumn{6}{|c|}{ Isıtma Sezonundaki Aylar } & \multirow[b]{2}{*}{$\begin{array}{c}\text { Sezonluk IDS } \\
{\left[{ }^{\circ} \text { Csaat }\right]}\end{array}$} \\
\hline & $\begin{array}{c}\text { Kasım } \\
{\left[{ }^{\circ} \text { Csaat }\right]}\end{array}$ & $\begin{array}{c}\text { Aralık } \\
{\left[{ }^{\circ} \text { Csaat }\right]}\end{array}$ & $\begin{array}{c}\text { Ocak } \\
{\left[{ }^{\circ} \text { Csaat }\right]}\end{array}$ & $\begin{array}{c}\text { Şubat } \\
{\left[{ }^{\circ} \text { Csaat }\right]}\end{array}$ & $\begin{array}{c}\text { Mart } \\
{\left[{ }^{\circ} \text { Csaat }\right]}\end{array}$ & $\begin{array}{c}\text { Nisan } \\
{\left[{ }^{\circ} \text { Csaat }\right]}\end{array}$ & \\
\hline 00:00-01:00 & 453,3 & 529,7 & 502,4 & 488,2 & 455,2 & 434,0 & 2862,9 \\
\hline 01:00-02:00 & 458,3 & 534,6 & 512,8 & 499,5 & 455,3 & 419,2 & 2879,6 \\
\hline 02:00-03:00 & 463,7 & 539,5 & 516,8 & 485,1 & 469,0 & 451,4 & 2925,5 \\
\hline 03:00-04:00 & 469,0 & 542,5 & 520,3 & 495,8 & 467,6 & 457,2 & 2952,4 \\
\hline 04:00-05:00 & 473,5 & 545,7 & 531,8 & 484,8 & 482,8 & 460,8 & 2979,3 \\
\hline 05:00-06:00 & 477,3 & 549,3 & 506,1 & 528,8 & 531,2 & 460,6 & 3053,2 \\
\hline 06:00-07:00 & 477,9 & 549,3 & 506,6 & 531,1 & 502,0 & 436,5 & 3003,5 \\
\hline 07:00-08:00 & 457,6 & 549,8 & 505,4 & 525,6 & 481,9 & 388,7 & 2909,0 \\
\hline 08:00-09:00 & 420,7 & 519,5 & 504,9 & 471,3 & 423,0 & 336,4 & 2675,8 \\
\hline 9:00-10:00 & 378,6 & 495,3 & 451,0 & 476,9 & 417,2 & 278,7 & 2497,7 \\
\hline $10: 00-11: 00$ & 340,8 & 467,0 & 429,9 & 475,6 & 402,2 & 252,2 & 2367,6 \\
\hline $11: 00-12: 00$ & 313,0 & 446,3 & 410,0 & 448,3 & 384,6 & 233,8 & 2236,1 \\
\hline $12: 00-13: 00$ & 294,8 & 429,0 & 417,4 & 419,4 & 370,7 & 220,1 & 2151,3 \\
\hline $13: 00-14: 00$ & 284,8 & 420,9 & 419,6 & 414,5 & 357,8 & 211,6 & 2109,2 \\
\hline $14: 00-15: 00$ & 291,0 & 424,1 & 444,7 & 448,0 & 362,1 & 218,4 & 2188,3 \\
\hline $15: 00-16: 00$ & 311,7 & 438,5 & 428,1 & 452,3 & 376,0 & 233,9 & 2240,4 \\
\hline $16: 00-17: 00$ & 345,3 & 460,3 & 485,2 & 473,6 & 399,0 & 255,2 & 2418,6 \\
\hline 17:00-18:00 & 373,3 & 478,7 & 433,8 & 421,0 & 426,5 & 287,1 & 2420,4 \\
\hline $18: 00-19: 00$ & 393,4 & 491,3 & 446,5 & 444,3 & 414,1 & 306,0 & 2495,6 \\
\hline $19: 00-20: 00$ & 499,8 & 499,8 & 460,1 & 437,1 & 400,3 & 350,4 & 2647,5 \\
\hline $20: 00-21: 00$ & 453,3 & 529,7 & 478,7 & 452,1 & 410,8 & 371,0 & 2582,5 \\
\hline $21: 00-22: 00$ & 458,3 & 534,6 & 496,0 & 469,6 & 418,5 & 392,1 & 2721,8 \\
\hline $22: 00-23: 00$ & 463,7 & 539,5 & 493,1 & 465,1 & 435,3 & 362,7 & 2716,7 \\
\hline $23: 00-24: 00$ & 469,0 & 542,5 & 499,0 & 480,5 & 461,4 & 418,2 & 2831,4 \\
\hline 24 Saatlik ToplamIDS Değeri & 473,5 & 545,7 & 11400,2 & 11288,4 & 10304,6 & 8236,0 & 62866,5 \\
\hline
\end{tabular}

Tablo 8, günün 12 saati (08:00-24:00 ) için $24^{\circ} \mathrm{C}$ İORS'na göre kesintili ısıtma sistemleri için hazırlanmıştır.

Tablo 8. Sakarya $24^{\circ} \mathrm{C}$ İç Ortam Referans Sıcaklığına Göre 12 Saatlik IDS Değeri (- 12- Hour Heating Degree Hour(HDH) Value According to $24^{\circ} \mathrm{C}$ Indoor Reference Temperature for Sakarya)

\begin{tabular}{|c|c|c|c|c|c|c|c|}
\hline \multicolumn{7}{|c|}{ Sakarya $24{ }^{\circ} \mathrm{C}$ İç Ortam Referans Sicaklığına Göre 12 Saat $(13: 00-17: 00)$ IDS Değeri } \\
\cline { 2 - 7 } $\begin{array}{c}\text { Bir saat aralıklarla } \\
12 \text { saat }\end{array}$ & $\begin{array}{c}\text { Kasım } \\
{\left[{ }^{\circ} \text { Csaat }\right]}\end{array}$ & $\begin{array}{c}\text { Aralı } \\
{\left[{ }^{\circ} \text { Csaat }\right]}\end{array}$ & $\begin{array}{c}\text { Ocak } \\
{\left[{ }^{\circ} \text { Csaat }\right]}\end{array}$ & $\begin{array}{c}\text { Şubat } \\
{\left[{ }^{\circ} \text { Csaat }\right]}\end{array}$ & $\begin{array}{c}\text { Mart } \\
{\left[{ }^{\circ} \text { Csaat }\right]}\end{array}$ & $\begin{array}{c}\text { Nisan } \\
{\left[{ }^{\circ} \text { Csaat }\right]}\end{array}$ & $\begin{array}{c}\text { Sezonluk IDS } \\
{\left[{ }^{\circ} \text { Csaat }\right]}\end{array}$ \\
\hline $9: 00-10: 00$ & 378,6 & 495,3 & 451,0 & 476,9 & 417,2 & 278,7 & 2497,7 \\
\hline $10: 00-11: 00$ & 340,8 & 467,0 & 429,9 & 475,6 & 402,2 & 252,2 & 2367,6 \\
\hline $11: 00-12: 00$ & 313,0 & 446,3 & 410,0 & 448,3 & 384,6 & 233,8 & 2236,1 \\
\hline $12: 00-13: 00$ & 294,8 & 429,0 & 417,4 & 419,4 & 370,7 & 220,1 & 2151,3 \\
\hline $13: 00-14: 00$ & 284,8 & 420,9 & 419,6 & 414,5 & 357,8 & 211,6 & 2109,2 \\
\hline $14: 00-15: 00$ & 291,0 & 424,1 & 444,7 & 448,0 & 362,1 & 218,4 & 2188,3 \\
\hline $15: 00-16: 00$ & 311,7 & 438,5 & 428,1 & 452,3 & 376,0 & 233,9 & 2240,4 \\
\hline $16: 00-17: 00$ & 345,3 & 460,3 & 485,2 & 473,6 & 399,0 & 255,2 & 2418,6 \\
\hline $17: 00-18: 00$ & 373,3 & 478,7 & 433,8 & 421,0 & 426,5 & 287,1 & 2420,4 \\
\hline $18: 00-19: 00$ & 393,4 & 491,3 & 446,5 & 444,3 & 414,1 & 306,0 & 2495,6 \\
\hline $19: 00-20: 00$ & 499,8 & 499,8 & 460,1 & 437,1 & 400,3 & 350,4 & 2647,5 \\
\hline 20:00-21:00 & 453,3 & 529,7 & 478,7 & 452,1 & 410,8 & 371,0 & 2582,5 \\
\hline 12 Saatlik Toplam IDS Değeri & 4279,8 & 5580,9 & 5305 & 5363,1 & 4721,3 & 3218,4 & 28355,2 \\
\hline
\end{tabular}


Tablo 9. Sakarya $25^{\circ} \mathrm{C}$ İç Ortam Referans Sıcaklığına Göre 24 Saatlik IDS Değeri (-24- Hour Heating Degree Hour(HDH) Value According to $25^{\circ} \mathrm{C}$ Indoor Reference Temperature for Sakarya)

\begin{tabular}{|c|c|c|c|c|c|c|c|}
\hline \multicolumn{8}{|c|}{ Sakarya $25^{\circ} \mathrm{C}$ İç Ortam Referans Sıcaklığına Göre 24 Saat IDS Değeri } \\
\hline \multirow{2}{*}{$\begin{array}{c}\text { Bir saat } \\
\text { aralıklarla } \\
24 \text { saat }\end{array}$} & \multicolumn{6}{|c|}{ Isitma Sezonundaki Aylar } & \multirow[b]{2}{*}{$\begin{array}{c}\text { Sezonluk IDS } \\
{\left[{ }^{\circ} \text { Csaat }\right]}\end{array}$} \\
\hline & $\begin{array}{c}\text { Kasım } \\
{\left[{ }^{\circ} \text { Csaat] }\right.}\end{array}$ & $\begin{array}{c}\text { Aralık } \\
{\left[{ }^{\circ} \text { Csaat }\right]}\end{array}$ & $\begin{array}{c}\text { Ocak } \\
{\left[{ }^{\circ} \text { Csaat }\right]}\end{array}$ & $\begin{array}{l}\text { Şubat } \\
{\left[{ }^{\circ} \mathrm{Csaat}\right]}\end{array}$ & $\begin{array}{c}\text { Mart } \\
{\left[{ }^{\circ} \text { Csaat }\right]}\end{array}$ & $\begin{array}{l}\text { Nisan } \\
{\left[{ }^{\circ} \mathrm{Csaat}\right]}\end{array}$ & \\
\hline 00:00-01:00 & 484,2 & 560,7 & 533,4 & 518,3 & 481,0 & 464,8 & 3042,4 \\
\hline 01:00-02:00 & 489,1 & 565,5 & 543,8 & 529,9 & 480,7 & 448,2 & 3057,2 \\
\hline 02:00-03:00 & 494,4 & 570,5 & 547,8 & 513,5 & 495,0 & 482,1 & 3103,4 \\
\hline 03:00-04:00 & 499,8 & 573,5 & 551,3 & 524,2 & 493,3 & 488,0 & 3130,1 \\
\hline 04:00-05:00 & 504,3 & 576,6 & 562,8 & 512,2 & 509,2 & 491,5 & 3156,6 \\
\hline 05:00-06:00 & 508,2 & 580,3 & 537,1 & 557,2 & 560,0 & 491,4 & 3234,1 \\
\hline 06:00-07:00 & 508,8 & 580,3 & 537,6 & 560,9 & 529,6 & 467,2 & 3184,5 \\
\hline 07:00-08:00 & 488,3 & 580,8 & 536,4 & 554,3 & 509,8 & 419,3 & 3088,7 \\
\hline 08:00-09:00 & 451,7 & 550,3 & 535,9 & 497,6 & 449,6 & 366,6 & 2851,6 \\
\hline 9:00-10:00 & 409,4 & 526,2 & 479,6 & 504,7 & 445,5 & 306,5 & 2672,0 \\
\hline $10: 00-11: 00$ & 371,4 & 497,9 & 457,1 & 504,3 & 431,6 & 279,9 & 2542,2 \\
\hline $11: 00-12: 00$ & 343,4 & 477,2 & 437,6 & 476,7 & 414,4 & 261,2 & 2410,5 \\
\hline $12: 00-13: 00$ & 324,9 & 459,8 & 444,6 & 447,0 & 400,4 & 246,9 & 2323,7 \\
\hline $13: 00-14: 00$ & 314,6 & 451,8 & 447,4 & 442,5 & 387,3 & 237,8 & 2281,3 \\
\hline $14: 00-15: 00$ & 321,0 & 454,8 & 473,7 & 478,1 & 391,5 & 244,8 & 2363,9 \\
\hline $15: 00-16: 00$ & 342,2 & 469,2 & 455,6 & 482,0 & 405,9 & 261,1 & 2415,9 \\
\hline $16: 00-17: 00$ & 376,0 & 491,3 & 515,5 & 503,7 & 429,3 & 283,6 & 2599,4 \\
\hline 17:00-18:00 & 404,1 & 509,7 & 462,3 & 448,6 & 457,0 & 316,5 & 2598,2 \\
\hline 18:00-19:00 & 424,3 & 522,3 & 476,7 & 472,1 & 441,9 & 334,9 & 2672,2 \\
\hline 19:00-20:00 & 530,8 & 530,8 & 490,3 & 465,6 & 426,0 & 381,1 & 2824,5 \\
\hline $20: 00-21: 00$ & 451,4 & 476,9 & 509,7 & 480,6 & 436,3 & 401,9 & 2756,7 \\
\hline $21: 00-22: 00$ & 462,8 & 544,8 & 527,0 & 498,5 & 443,7 & 423,0 & 2899,8 \\
\hline $22: 00-23: 00$ & 472,9 & 549,5 & 524,1 & 493,7 & 461,0 & 390,3 & 2891,5 \\
\hline $23: 00-24: 00$ & 479,8 & 554,3 & 530,0 & 510,7 & 488,1 & 449,1 & 3012,1 \\
\hline 24 saatlik toplam & 10457,9 & 12655,0 & 12117,4 & 11976,8 & 10967,9 & 8937,3 & 67112,3 \\
\hline
\end{tabular}

Tablo 10, günün 11 saati (08:00-18:00) için $25^{\circ} \mathrm{C}$ İORS’na göre kesintili ısıtma sistemleri için hazırlanmıştır.

Tablo 10. Sakarya $25^{\circ} \mathrm{C}$ İç Ortam Referans Sıcaklığına Göre 11 Saatlik IDS Değeri (- 11- Hour Heating Degree Hour(HDH) Value According to $25^{\circ} \mathrm{C}$ Indoor Reference Temperature for Sakarya)

\begin{tabular}{|c|c|c|c|c|c|c|c|}
\hline \multicolumn{8}{|c|}{ Sakarya $25^{\circ} \mathrm{C}$ İç Ortam Referans Sicakliğina Göre 11 Saat (08:00- 17:00) Arasindaki IDS Değeri } \\
\hline \multirow{2}{*}{$\begin{array}{c}\text { Bir saat } \\
\text { aralıklarla } \\
11 \text { saat } \\
\end{array}$} & \multicolumn{6}{|c|}{ Isıtma Sezonundaki Aylar } & \multirow[b]{2}{*}{$\begin{array}{c}\text { Sezonluk IDS } \\
{\left[{ }^{\circ} \text { Csaat }\right]}\end{array}$} \\
\hline & $\begin{array}{c}\text { Kasım } \\
{\left[{ }^{\circ} \text { Csaat }\right]}\end{array}$ & $\begin{array}{c}\text { Aralık } \\
{\left[{ }^{\circ} \text { Csaat }\right]}\end{array}$ & $\begin{array}{c}\text { Ocak } \\
{\left[{ }^{\circ} \text { Csaat }\right]}\end{array}$ & $\begin{array}{c}\text { Şubat } \\
{\left[{ }^{\circ} \text { Csaat }\right]}\end{array}$ & $\begin{array}{c}\text { Mart } \\
{\left[{ }^{\circ} \text { Csaat }\right]}\end{array}$ & $\begin{array}{c}\text { Nisan } \\
{\left[{ }^{\circ} \text { Csaat }\right]}\end{array}$ & \\
\hline 08:00-09:00 & 451,7 & 550,3 & 535,9 & 497,6 & 449,6 & 366,6 & 2851,6 \\
\hline 9:00-10:00 & 409,4 & 526,2 & 479,6 & 504,7 & 445,5 & 306,5 & 2672,0 \\
\hline 10:00-11:00 & 371,4 & 497,9 & 457,1 & 504,3 & 431,6 & 279,9 & 2542,2 \\
\hline 11:00-12:00 & 343,4 & 477,2 & 437,6 & 476,7 & 414,4 & 261,2 & 2410,5 \\
\hline 12:00-13:00 & 324,9 & 459,8 & 444,6 & 447,0 & 400,4 & 246,9 & 2323,7 \\
\hline $13: 00-14: 00$ & 314,6 & 451,8 & 447,4 & 442,5 & 387,3 & 237,8 & 2281,3 \\
\hline $14: 00-15: 00$ & 321,0 & 454,8 & 473,7 & 478,1 & 391,5 & 244,8 & 2363,9 \\
\hline $15: 00-16: 00$ & 342,2 & 469,2 & 455,6 & 482,0 & 405,9 & 261,1 & 2415,9 \\
\hline $16: 00-17: 00$ & 376,0 & 491,3 & 515,5 & 503,7 & 429,3 & 283,6 & 2599,4 \\
\hline $17: 00-18: 00$ & 404,1 & 509,7 & 462,3 & 448,6 & 457,0 & 316,5 & 2598,2 \\
\hline 11 saatlik toplam & 3658,7 & 4888,2 & 4709,3 & 4785,2 & 4212,5 & 2804,9 & 25058,7 \\
\hline
\end{tabular}


Tablo 11. Sakarya $26^{\circ} \mathrm{C}$ İç Ortam Referans Sıcaklığına Göre 24 Saatlik IDS Değeri (-24- Hour Heating Degree Hour(HDH) Value According to $26^{\circ} \mathrm{C}$ Indoor Reference Temperature for Sakarya)

\begin{tabular}{|c|c|c|c|c|c|c|c|}
\hline \multicolumn{8}{|c|}{ Sakarya $26^{\circ} \mathrm{C}$ İç Ortam Referans Sıcaklığına Göre 24 Saat IDS Değeri } \\
\hline \multirow{2}{*}{$\begin{array}{c}\text { Bir saat aralıklarla } \\
24 \text { saat }\end{array}$} & \multicolumn{6}{|c|}{ Isıtma Sezonundaki Aylar } & \multirow[b]{2}{*}{$\begin{array}{c}\text { Sezonluk IDS } \\
{\left[{ }^{\circ} \text { Csaat }\right]}\end{array}$} \\
\hline & $\begin{array}{c}\text { Kasım } \\
{\left[{ }^{\circ} \text { Csaat }\right]}\end{array}$ & $\begin{array}{c}\text { Aralık } \\
{\left[{ }^{\circ} \text { Csaat] }\right.}\end{array}$ & $\begin{array}{c}\text { Ocak } \\
{\left[{ }^{\circ} \text { Csaat }\right]}\end{array}$ & $\begin{array}{c}\text { Şubat } \\
{\left[{ }^{\circ} \text { Csaat }\right]}\end{array}$ & $\begin{array}{c}\text { Mart } \\
{\left[{ }^{\circ} \text { Csaat }\right]}\end{array}$ & $\begin{array}{c}\text { Nisan } \\
{\left[{ }^{\circ} \text { Csaat }\right]}\end{array}$ & \\
\hline 00:00-01:00 & 515,1 & 591,7 & 564,4 & 549,3 & 506,7 & 495,7 & 3222,9 \\
\hline 01:00-02:00 & 520,0 & 596,5 & 574,8 & 560,9 & 506,2 & 477,4 & 3235,7 \\
\hline 02:00-03:00 & 525,3 & 601,5 & 578,8 & 543,7 & 520,9 & 512,9 & 3283,1 \\
\hline 03:00-04:00 & 530,7 & 604,5 & 582,4 & 554,3 & 519,0 & 518,8 & 3309,6 \\
\hline 04:00-05:00 & 535,2 & 607,6 & 593,8 & 541,2 & 535,5 & 522,2 & 3335,5 \\
\hline 05:00-06:00 & 539,1 & 611,3 & 568,1 & 586,7 & 588,8 & 522,1 & 3416,2 \\
\hline 06:00-07:00 & 539,8 & 611,3 & 568,6 & 591,6 & 557,2 & 498,1 & 3366,5 \\
\hline 07:00-08:00 & 519,0 & 611,8 & 567,4 & 584,0 & 537,6 & 449,9 & 3269,7 \\
\hline 08:00-09:00 & 482,7 & 581,3 & 566,9 & 525,5 & 476,2 & 396,9 & 3029,4 \\
\hline 9:00-10:00 & 440,3 & 557,1 & 509,8 & 533,8 & 473,9 & 334,7 & 2849,7 \\
\hline $10: 00-11: 00$ & 402,1 & 528,8 & 485,9 & 533,5 & 461,1 & 308,3 & 2719,8 \\
\hline $11: 00-12: 00$ & 374,1 & 508,2 & 467,0 & 505,6 & 444,3 & 289,4 & 2588,7 \\
\hline $12: 00-13: 00$ & 355,3 & 490,7 & 473,5 & 475,3 & 430,6 & 274,6 & 2500,0 \\
\hline 13:00-14:00 & 344,9 & 482,6 & 476,6 & 471,1 & 417,2 & 265,0 & 2457,5 \\
\hline $14: 00-15: 00$ & 351,4 & 485,6 & 503,7 & 508,2 & 421,4 & 272,2 & 2542,6 \\
\hline $15: 00-16: 00$ & 372,8 & 500,1 & 484,6 & 512,0 & 436,0 & 289,2 & 2594,8 \\
\hline $16: 00-17: 00$ & 406,8 & 522,2 & 546,2 & 534,4 & 459,9 & 312,7 & 2782,3 \\
\hline 17:00-18:00 & 435,1 & 540,6 & 492,4 & 477,8 & 487,6 & 346,4 & 2779,9 \\
\hline $18: 00-19: 00$ & 455,3 & 553,3 & 507,7 & 501,6 & 469,6 & 363,9 & 2851,4 \\
\hline $19: 00-20: 00$ & 561,7 & 561,7 & 521,3 & 495,7 & 451,6 & 411,9 & 3004,0 \\
\hline $20: 00-21: 00$ & 482,3 & 505,3 & 540,7 & 510,7 & 461,8 & 432,8 & 2933,6 \\
\hline $21: 00-22: 00$ & 493,8 & 575,8 & 558,0 & 528,8 & 469,0 & 453,9 & 3079,2 \\
\hline $22: 00-23: 00$ & 503,9 & 580,5 & 555,1 & 523,9 & 487,5 & 417,9 & 3068,7 \\
\hline $23: 00-24: 00$ & 510,8 & 585,3 & 561,0 & 541,7 & 514,8 & 479,9 & 3193,5 \\
\hline 24 saatlik toplam & 11197,4 & 13395,3 & 12848,8 & 12691,2 & 11634,5 & 9646,9 & 71414,1 \\
\hline
\end{tabular}

Tablo 12, Onaltı saat (08:00-18:00) çalışacak $27^{\circ} \mathrm{C}$ IOORS'na göre kesintili ısıtma sistemleri için hazırlanmıștır.

Tablo 12. Sakarya $27^{\circ} \mathrm{C}$ İç Ortam Referans Sıcaklığına Göre 16 Saatlik IDS Değeri (-16-Hour Heating Degree Hour(HDH) Value According to $27^{\circ} \mathrm{C}$ Indoor Reference Temperature for Sakarya)

\begin{tabular}{|c|c|c|c|c|c|c|c|}
\hline \multicolumn{8}{|c|}{ Sakarya $27^{\circ} \mathrm{C}$ İç Ortam Referans Sicakliğina Göre 16 Saatlik (08:00 - 24:00) IDS Değeri } \\
\hline \multirow{2}{*}{$\begin{array}{c}\text { Bir saat } \\
\text { arallklarla } \\
16 \text { saat }\end{array}$} & \multicolumn{6}{|c|}{ ISITMA SEZONUNDAKİ AYLAR } & \multirow[b]{2}{*}{$\begin{array}{c}\text { Sezonluk IDS } \\
{\left[{ }^{\circ} \mathrm{Csaat}\right]}\end{array}$} \\
\hline & $\begin{array}{c}\text { Kasım } \\
{\left[{ }^{\circ} \text { Csaat }\right]}\end{array}$ & $\begin{array}{c}\text { Aralık } \\
{\left[{ }^{\circ} \text { Csaat }\right]}\end{array}$ & $\begin{array}{c}\text { Ocak } \\
{\left[{ }^{\circ} \text { Csaat }\right]}\end{array}$ & $\begin{array}{c}\text { SSubat } \\
{\left[{ }^{\circ} \text { Csaat }\right]}\end{array}$ & $\begin{array}{c}\text { Mart } \\
{\left[{ }^{\circ} \text { Csaat }\right]}\end{array}$ & $\begin{array}{c}\text { Nisan } \\
{\left[{ }^{\circ} \text { Csaat }\right]}\end{array}$ & \\
\hline 08:00-09:00 & 513,6 & 612,3 & 597.9 & 554,8 & 503,5 & 427,4 & 3209,4 \\
\hline 9:00-10:00 & 471,3 & 588,1 & 540,8 & 563,9 & 502,3 & 363,1 & 3029,5 \\
\hline 10:00-11:00 & 433,0 & 559,8 & 516,2 & 563,5 & 490,6 & 337,1 & 2900,2 \\
\hline 11:00-12:00 & 404,9 & 539,2 & 497,6 & 535,4 & 474,4 & 318,4 & 2769,9 \\
\hline 12:00-13:00 & 385,9 & 521,6 & 503,3 & 504,7 & 461,0 & 303,3 & 2679,9 \\
\hline $13: 00-14: 00$ & 375,5 & 513,5 & 506,9 & 500,9 & 447,5 & 293,1 & 2637,3 \\
\hline $14: 00-15: 00$ & 382,0 & 516,6 & 534,3 & 538,6 & 451,8 & 300,6 & 2723,7 \\
\hline $15: 00-16: 00$ & 403,7 & 531,0 & 514,8 & 542,5 & 466,5 & 318,2 & 2776,7 \\
\hline 16:00-17:00 & 437,7 & 553,2 & 577,2 & 565,3 & 490,7 & 342,4 & 2966,4 \\
\hline 17:00-18:00 & 466,0 & 571,6 & 523,4 & 508,2 & 518,2 & 376,9 & 2964,3 \\
\hline 18:00-19:00 & 486,2 & 584,2 & 538,7 & 532,2 & 497,4 & 393,0 & 3031,8 \\
\hline 19:00-20:00 & 592,7 & 592,7 & 552,3 & 526,7 & 477,3 & 442,7 & 3184,6 \\
\hline 20:00-21:00 & 513,2 & 535,4 & 571,7 & 541,7 & 487,3 & 463,7 & 3113,1 \\
\hline 21:00-22:00 & 524,7 & 606,8 & 589,0 & 559,8 & 495,1 & 484,9 & 3260,2 \\
\hline $22: 00-23: 00$ & 534,9 & 611,4 & 586,1 & 554,9 & 515,4 & 445,5 & 3248,2 \\
\hline 23:00-24:00 & 541,7 & 616,3 & 592,0 & 572,7 & 541,5 & 510,8 & 3375,1 \\
\hline 16 saatlik toplam IDS Değeri & 6925,3 & 8437,4 & 8150,2 & 8093,1 & 7279 & 5610,3 & 44495,2 \\
\hline
\end{tabular}


Tablo 13, onaltı saat (08:00-18:00) çalışacak 27 ve $28^{\circ} \mathrm{C}$ İORS'na göre kesintili ısıtma sistemleri IDS değerlerinin mukayesesi için hazırlanmıștır. Tablo 12 'de 27 İORS'na göre sezonluk IDS değeri 44495.2 SDS iken İORS $28{ }^{\circ} \mathrm{C}$ çıarıldığında IDS değeri \%14 artarak 50788.2 IDS olacağı Tablo 13'te görülmektedir.

Tablo 13. Sakarya $27^{\circ} \mathrm{C}$ İç Ortam Referans Sıcaklığına Göre 16 Saatlik IDS Değeri (-16 Hour Heating Degree Hour(HDH) Value According to $28^{\circ} \mathrm{C}$ Indoor Reference Temperature for Sakarya)

\begin{tabular}{|c|c|c|c|c|c|c|c|}
\hline \multicolumn{8}{|c|}{ Sakarya $28^{\circ} \mathrm{C}$ İç Ortam Referans Sicakliğina Göre 16 Saat (08:00- 24:00) Arasindaki IDS Değeri } \\
\hline \multirow[b]{2}{*}{$\begin{array}{c}\text { Bir saat aralıklarla } \\
24 \text { saat }\end{array}$} & \multicolumn{6}{|c|}{ ISITMA SEZONUNDAKİ AYLAR } & \multirow[b]{2}{*}{$\begin{array}{c}\text { Sezonluk IDS } \\
{\left[{ }^{\circ} \text { Csaat }\right]}\end{array}$} \\
\hline & $\begin{array}{c}\text { Kasım } \\
{\left[{ }^{\circ} \text { Csaat }\right]}\end{array}$ & $\begin{array}{c}\text { Aralık } \\
{\left[{ }^{\circ} \text { Csaat }\right]}\end{array}$ & $\begin{array}{c}\text { Ocak } \\
{\left[{ }^{\circ} \text { Csaat }\right]}\end{array}$ & $\begin{array}{c}\text { Şubat } \\
{\left[{ }^{\circ} \text { Csaat }\right]}\end{array}$ & $\begin{array}{c}\text { Mart } \\
{\left[{ }^{\circ} \text { Csaat }\right]}\end{array}$ & $\begin{array}{c}\text { Nisan } \\
{\left[{ }^{\circ} \text { Csaat }\right]}\end{array}$ & \\
\hline 08:00-09:00 & 544,6 & 643,3 & 628,9 & 585,2 & 532,1 & 458,0 & 3392,0 \\
\hline $9: 00-10: 00$ & 502,2 & 619,1 & 571,8 & 594,6 & 530,7 & 391,8 & 3210,4 \\
\hline $10: 00-11: 00$ & 463,9 & 590,8 & 547,2 & 594,0 & 520,2 & 366,3 & 3082,3 \\
\hline $11: 00-12: 00$ & 435,9 & 570,2 & 528,6 & 565,9 & 504,5 & 347,7 & 2952,8 \\
\hline $12: 00-13: 00$ & 416,7 & 552,6 & 533,9 & 535,1 & 491,4 & 332,6 & 2862,4 \\
\hline $13: 00-14: 00$ & 406,3 & 544,4 & 537,7 & 531,4 & 477,9 & 321,9 & 2819,7 \\
\hline $14: 00-15: 00$ & 412,7 & 547,5 & 565,1 & 569,3 & 482,3 & 329,6 & 2906,5 \\
\hline $15: 00-16: 00$ & 434,5 & 561,9 & 545,5 & 573,2 & 497,3 & 347,8 & 2960,2 \\
\hline $16: 00-17: 00$ & 468,6 & 584,2 & 608,2 & 596,2 & 521,5 & 372,6 & 3151,3 \\
\hline $17: 00-18: 00$ & 496,9 & 602,5 & 554,4 & 539,2 & 548,9 & 407,5 & 3149,5 \\
\hline 18:00-19:00 & 517,2 & 615,2 & 569,7 & 563,2 & 525,2 & 422,2 & 3212,8 \\
\hline 19:00-20:00 & 623,7 & 623,7 & 583,3 & 557,7 & 503,9 & 473,6 & 3366,0 \\
\hline $20: 00-21: 00$ & 544,2 & 566,4 & 602,7 & 572,7 & 513,6 & 494,7 & 3294,3 \\
\hline $21: 00-22: 00$ & 555,7 & 637,8 & 620,0 & 590,8 & 522,9 & 515,8 & 3442,9 \\
\hline $22: 00-23: 00$ & 565,9 & 642,4 & 617,0 & 585,9 & 544,6 & 473,1 & 3429,0 \\
\hline $23: 00-24: 00$ & 572,6 & 647,3 & 623,0 & 603,7 & 568,3 & 541,7 & 3556,6 \\
\hline 16 saatlik toplam IDS Değeri & 7961,6 & 9549,3 & 9237 & 9158,1 & 8285,3 & 6596,9 & 50788,2 \\
\hline
\end{tabular}

Tablo 3, 5, 7, 9, 11,12, 13'te 20,22, 24, 25 26, 27 ve $28^{\circ} \mathrm{C}$ İORS için isıttma dönemindeki tüm aylar ve sezonluk IDS değeri; en yüksek 06:00- 07:00 saaatleri arasında, en düşük ise 13:00-14:00 saatleri arasında olduğu görülmektedir.

Sakarya için 06:00- 07:00 arasındaki IDS değerleri 20, 22 ve $27^{\circ} \mathrm{C}$ İORS'larına göre Tablo 14 örnek olarak verilmiştir. Bu tabloda en yüksek ısıtma enerji ihtiyacı üç farklı İORS içinde ocak ayında 06:00- 07:00 saatleri arasında olduğu görülmektedir. Sakarya'daki bir binada ocak ayı için $20^{\circ} \mathrm{C}$ İORS için IDS değeri $394^{\circ} \mathrm{C}$.saat, İORS $22^{\circ} \mathrm{C}$ seçildiğinde IDS değeri $\% 11.35$ artmakta, $27^{\circ} \mathrm{C}$ seçildiğinde ise IDS değeri $\% 52$ artmaktadır. Getirilen bu yaklaşımla ısıtma dönemindeki her ayın 24 saati için 11 farklı IORS'na göre ısıtma enerji ihtiyacı aylık ve sezonluk olarak ayrıntılı olarak ortaya konulmuştur.

Tablo 14. Sakarya 06:00- 07:00 Saatleri Arasında Farklı İORS Göre IDS Değeri (Sakarya Heating Degree Hour Value Between 06:00 - 07:00 According to Different Indoor Reference Temperature)

\begin{tabular}{|c|c|c|c|c|c|c|c|}
\hline \multicolumn{7}{|c|}{ Sakarya 06:00- 07:00 Saatleri Arasında Farklı İORS Göre IDSD } \\
\hline Farklı İORS IDSD & $\begin{array}{c}\text { Kasım } \\
{\left[{ }^{\circ} \mathrm{Csaat}\right]}\end{array}$ & $\begin{array}{c}\text { Aralı } \\
{\left[{ }^{\circ} \mathrm{Csaat}\right]}\end{array}$ & $\begin{array}{c}\text { Ocak } \\
{\left[{ }^{\circ} \mathrm{Csaat}\right]}\end{array}$ & $\begin{array}{c}\text { Şubat } \\
{\left[{ }^{\circ} \mathrm{Csaat}\right]}\end{array}$ & $\begin{array}{c}\text { Mart } \\
{\left[{ }^{\circ} \mathrm{Csaat}\right]}\end{array}$ & $\begin{array}{c}\text { Nisan } \\
{\left[{ }^{\circ} \mathrm{Csaat}\right]}\end{array}$ & $\begin{array}{c}\text { Sezonluk } \\
\text { IDS } \\
{\left[{ }^{\circ} \mathrm{Csaat}\right]}\end{array}$ \\
\hline $20^{\circ} \mathrm{C}$ İORS IDSD & 354,6 & 425,6 & 394,0 & 421,9 & 391,9 & 314,1 & 2302,2 \\
\hline $22^{\circ} \mathrm{C}$ İORS IDSD & 416,2 & 487,4 & 447,3 & 475,2 & 446,9 & 375,1 & 2648,1 \\
\hline $27^{\circ} \mathrm{C}$ İORS IDSD & 570,7 & 642,3 & 599,6 & 622,6 & 585,4 & 528,9 & 3549,5 \\
\hline
\end{tabular}

Şekil 1'de $22^{\circ} \mathrm{C}$ iç ortam referans sıcaklığına göre IDS değeri verilmiştir. Bu şekilde sezon gününün her saati için ısıtma enerji ihtiyacındaki değişim görülmektedir. Bu yaklaşımla Sakarya ilinin saatlik bazda ısıtma sistemlerinin sezonluk tüketeceği enerji tahmini yapılabilir. 


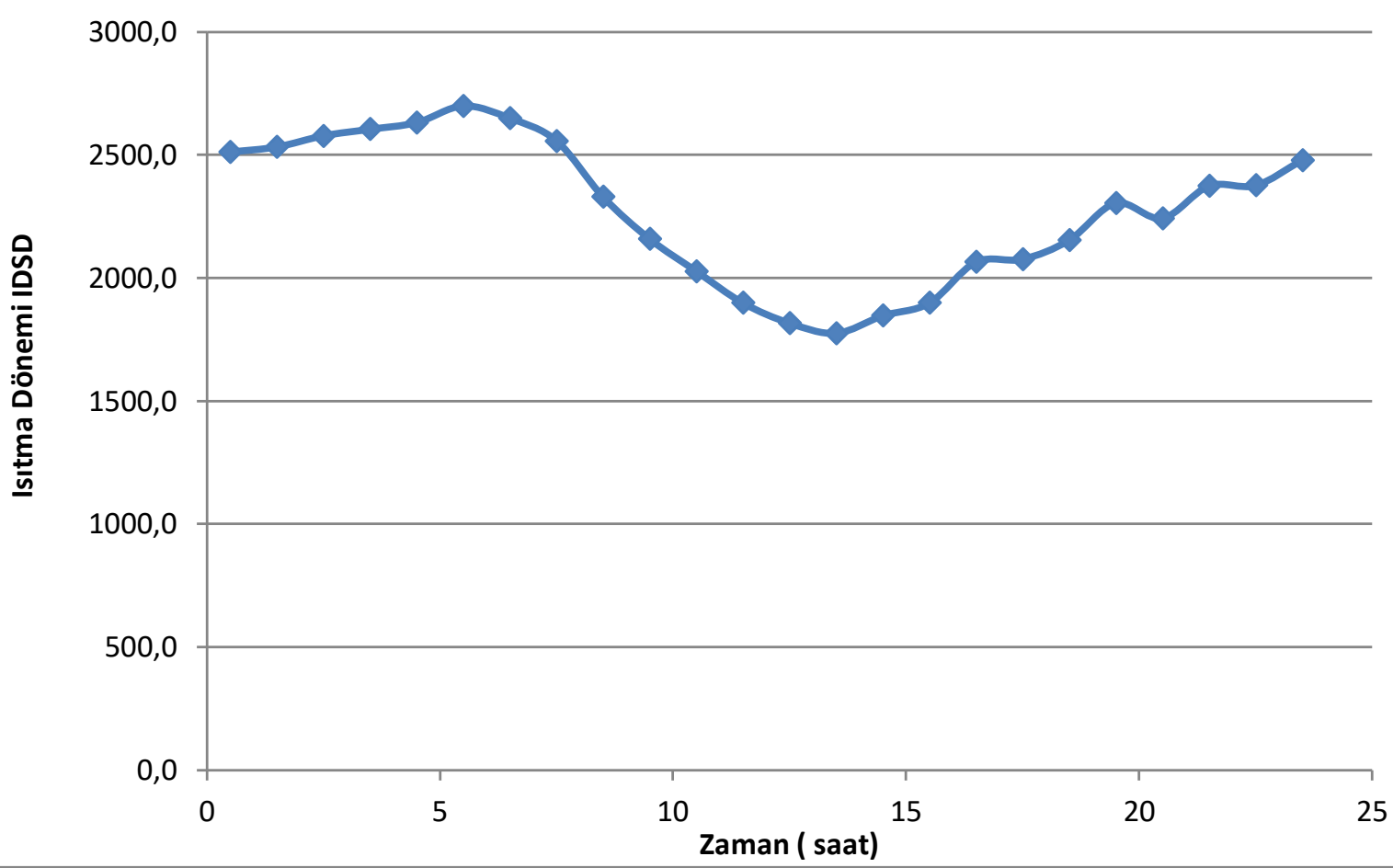

Şekil 1. $23^{\circ} \mathrm{C}$ İç Ortam Referans Sıcaklığına Göre IDS Değeri (Fig Heating Degree Hour Value According To $23^{\circ} \mathrm{C}$ Indoor Reference Temperature)

Şekil 2 'de $22^{\circ} \mathrm{C}$ iç ortam referans sıcaklığına göre ısıtma dönemindeki her bir ay için IDSD verilmiştir. Bu şekilde sezonun her saati için ısıtma enerji ihtiyacındaki değişim görülmektedir. Bu yaklaşımla Sakarya ilinin saatlik bazda ısıtma sistemlerinin sezondaki her ay için sezonluk tüketeceği enerji tahmini yapılabilir.

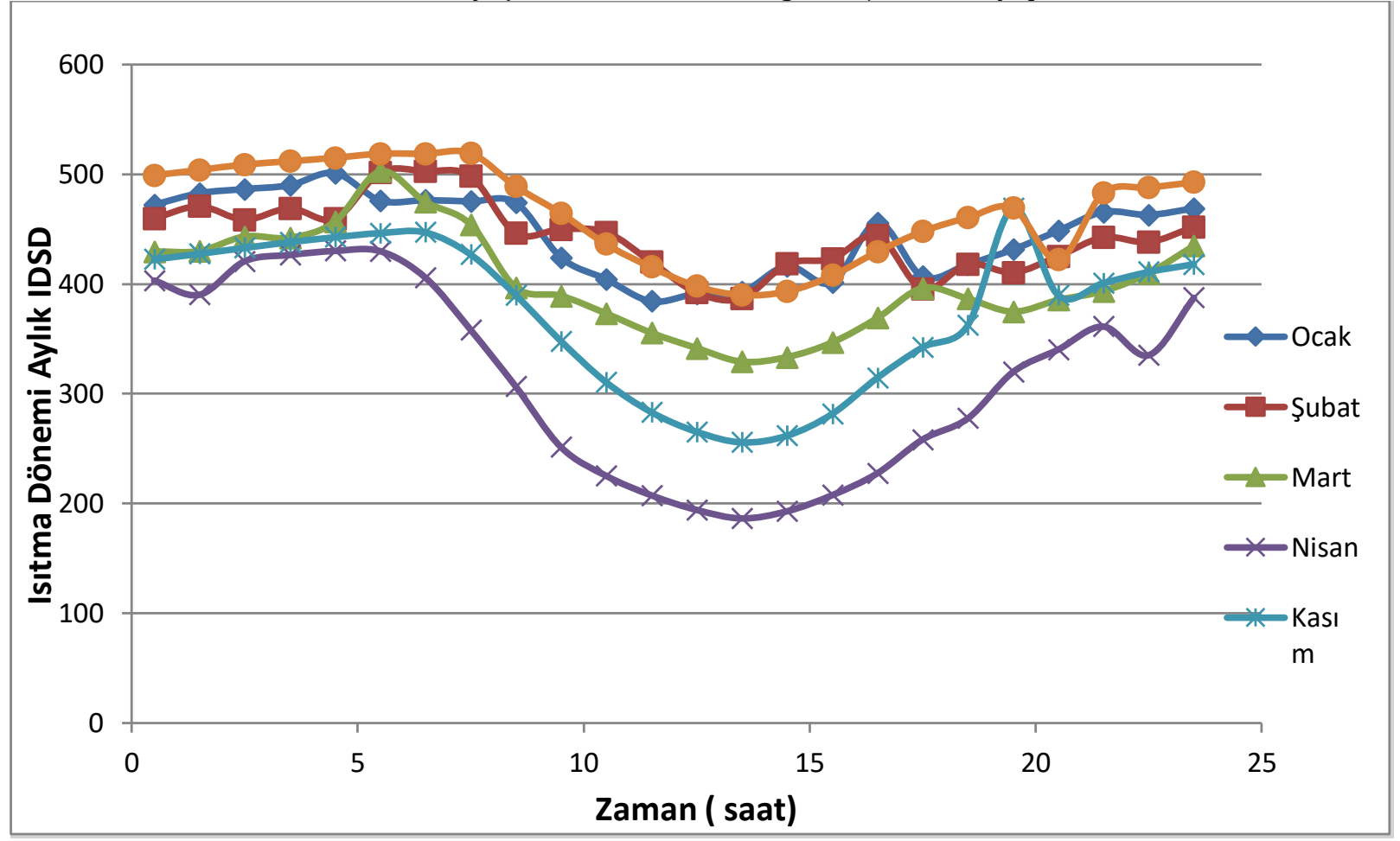

Şekil 2. $23^{\circ} \mathrm{C}$ İç Ortam Referans Sıcaklığına Göre Isıtma Dönemi Her Ayı İçin Isıtma Derece Saat Değeri (Heating Degree Hour Value For Each Month of the Heating Period According to $23^{\circ} \mathrm{C}$ Indoor Reference Temperature)

Bu çalışma on bir RİOS ve günün yirmi dört saati için yapılmıştır. Makale metninin uzamaması için sadece Şekil 1 ve 2'deki yaklaşımlar metinde verilmiştir. Bu yaklaşımlar ısıtma dönemindeki toplam ve dönemdeki her ay için 24 saatlik enerji talebi tahmini için önem arzetmektedir. 
Bu çalışmayla Tablo 1-5 ve Şekil 1-2 ilk defa Sakarya için literatüre kazandırılmıștır. Bu çalışma ısıtma sistemi kullanıcıları, üreticileri, yerel yönetimler ve elektrik dağıtım firmaları için önem arz etmektedir.

\section{Sonuç (Conclusion)}

Sakarya ili için yapılan bu çalışmadan elde edilen sonuçlar;

i. YODHSD'la Isıtma dönemi başlangıcı ve bitişi tespit edilmiștir. Bu yaklaşım $18^{\circ} \mathrm{C}$ ve altındaki dış hava sıcaklığının 8760 saat içerisinde görülme sıklığı günün yirmi dört saati için her ay, sezonluk olarak ortaya konulmuştur. Literatüre getirilen bu yaklaşımla ısıtma sistemlerinin toplam çalışma süreleri sezondaki her ay için, herhangi iki ay arası için bulunabilir. Ayrıca sezonluk olarakta ısıtma sistemlerinin çalışma süreleri tahmin edilebilecektir.

ii. 11 farklı iç ortam referans sıcaklı̆̆ına $\left(18-28^{\circ} \mathrm{C}\right)$ göre Sakarya için IDS değerleri ayrıntılı olarak hesaplanmıştır. Bu yaklaşımla ısıtma dönemindeki her ayın istenilen saatinde, herhangi iki zaman diliminde ve günün her saatine göre ayrı ayrı ID değeri sezondaki her ay, günün 24 saati için ayrı ayrı olarak tahmin edilerek literature kazandırmıștır.

iii. Isıtma dönemindeki tüm ayların 24 saatlik IDS değeri ve sezondaki tüm ayların 24 saatlik IDS değeri değişim eğrileri literatüre sunulmuştur. Bu yaklaşım konuyla ilgilenen akademisyenler, makina mühendislerine yardımcı olacağı düşünülmektedir.

iv. Bu çalışmayla ısıtma sistemlerinin çalışma süreleri aylık, sezonluk olarak tahmin edilmesi, her il için farklı garanti sürelerinin gündeme gelmesi düşünülmektedir

v. $20-28^{\circ} \mathrm{C}$ İORS'da ısıtma dönemindeki tüm aylar ve sezonluk IDSD; en yüksek 06:00- 07:00 saaatleri arasında, en düşük ise 13:00-14:00 saatleri arasında olacağı tahmin edilmiştir.

vi. En yüksek ısıtma enerji ihtiyacı on bir farklı İOS içinde Ocak ayında 06:00- 07:00 saatleri arasında olacağı tespit edilmiștir.

vii. Yalıtımsız bir binada kasım ayı için $22^{\circ} \mathrm{C}$ IORS için IDSD $443,6^{\circ} \mathrm{C}$-saat, İORS $27^{\circ} \mathrm{C}$ çıarılldı̆̆ında ise IDSD $\% 35$ artarak 597,9 ${ }^{\circ} \mathrm{C}$-Saat olmaktadır. Getirilen bu yaklaşımla ısıtma dönemindeki herhangi bir ayın herhangi bir saatinde, herhangi iki zaman dilim arasında IDSD aylık, sezonluk olarak 11 farklı IORS'na göre bulunacaktır.

viii. Sakarya ilinde kesintili çalışacak binalarda(ofis, banka, resmi kurumlar) kullanılacak hava kaynaklı isı pompaları COP hesaplamaları için parametre olacaktır.

\section{Çıkar Çatışması (Conflict of Interest)}

Yazarlar tarafından herhangi bir çıkar çatışması beyan edilmemiştir. No conflict of interest was declared by the authors.

\section{Kaynaklar (References)}

Badescu, V., Zamfir, 1999. E. Degree-days, degree-hours and ambient temperature bin data from monthly-average temperatures in Romania. Energy Conversion and Management 40 (8) : 885-900.

Bulut, H., Büyükalaca, O., Yılmaz, T., Aktacir, M. A.. 2002. GAP Bölgesi İçin Detaylı İklim Verileri. Harran Üniversitesi GAP IV. Mühendislik Kongresi 183-191. Şanlıurfa.

Büyükalaca, O. Bulut, H.. 2003. Detailed weather data for the provinces covered by the Southeastern Anatolia Project(GAP) of Turkey. Applied Energy, 77: 187-204.

Büyükalaca, O., Bulut, H.,Yllmaz, T., 2001, Analysis of variable-base heating and cooling degree-days for Turkey, Applied Energy, 69 (4): 269-283.

Coskun, C., 2010. A novel approach to degree-hour calculation: Indoor and outdoor reference temperature based degree-hour calculation. Energy 35: 2455-2460.

Coşkun, C., Oktay Z., Ertürk M.,2009. Konutların Isıtma Sezonunda Seçilen İç Ortam Sıcaklık Parameteresinin Enerji-MaliyetÇevre Açısından Değerlendirilmesi ve Bir Uygulama Örneği. IX. Ulusal Tesisat Mühendisliği Kongresi. 529-538. İzmir.

Dilmaç, S., Kesen, N.,2003. A comparison of new Turkish thermal insulation in building. Energy \&Building 35 (2): $161-174$

Dombayci, A., 2009. Degree-days maps of Turkey for various base temperatures.. Energy 34 (11):1807-1812.

Durmayaz A., Kadığlu M., 2003. Heating energy requirements and fuel consumptions in the biggest city centers of Turkey. Energy Conversion and Management 44 (7): 1177-1192.

Durmazayaz, A., Kadıoğlu, M. ve Şen., Z., 2000. An application of the degree-hours method to estimate the residential heating energy requirement and fuel consumption in Istanbul. Energy 25 (12) : 1245-1256.

Haas, R., Auer, H., Biermayr, P., 1998. The impact of consumer behavior on residential energy demand for space heating. Energy and Buildings. 27:195-205.

Oktay, Z., Coskun, C., Dincer, I., 2011. A new approach for predicting cooling degree hours and energy requirements in buildings, Energy 36: 4855-4863.

Sarak, H., Satman, A., 2001. The degree-day method to estimate the residential heating natural gas consumption in Turkey: a case study. Energy 28: 929-39.

Sarak.H., Satman., A., 2003. The degree-day method to estimate the residential heating natural gas consumption in Turkey: a case study. Energy (28): 929-939. 